\title{
Satellite derived aerosol optical depth climatology over tropical coastal station Machilipatnam, India
}

\author{
A.S. Madhusudanacharyulu“, K. Samatha, K. Sailesh Kumar, K. Jagadeesh, \\ Suneetha Rani J.
}

Department of Physics, Andhra University, Visakhapatnam, India.

*E-mail address: madhu.acharyulu@gmail.com

\begin{abstract}
Keywords: Aerosol optical depth; frequency distribution; temporal variation; Synoptic wind patterns; OMI
\end{abstract}

\begin{abstract}
Climatological aerosol optical depths (AOD) over Tropical coastal city Machilipatnam, India have been examined to bring out the temporal heterogeneity in columnar aerosol characteristics. AOD values at $388 \mathrm{~nm}$ derived from the Ozone Monitoring Instrument (OMI) sensor EOS-AURA satellite, for the period of 2005-2013 have been analyzed for the purpose. AOD trends exhibited seasonal annual mean variations. Frequency distributions of the AOD values are examined to infer the monthly mean values. Monthly and seasonal variations of AOD are investigated in the light of regional synoptic meteorology. AODs $>0.6$ showed maximum occurrence in monsoon months. The mean AOD values increased towards summer reaching $\sim 0.69 \pm$ 0.34 and attained peak in monsoon season with a value of $\sim 0.74 \pm 0.33$ and decreased during postmonsoon reaching as low as $\sim 0.73 \pm 0.3$. Positive slope $\sim 0.016$ observed for inter annual distribution trend line. Factors like synoptic scale circulation patterns which are causing modulations of AOD apart from local sources were discussed.
\end{abstract}

\section{INTRODUCTION}

Aerosols, which are microscopic particles suspended in the atmosphere are key components of the climate system. Apart from their crucial role in air pollution, aerosols influence the climate directly and indirectly through radiative forcing (Badrinath and Madhavi Latha, 2006; Takamura et al., 2007; Khatri et al., 2009). Direct radiative forcing includes the scattering and absorption of the incoming solar radiation by aerosols, which in turn cools the earth's surface (Ramanthan and Crutzen, 2003; Panicker et al., 2008). Aerosols influence the climate indirectly by altering cloud microphysical properties and hence increasing albedo and cloud life time (Twomey, 1977; Albrecht, 1989; Panicker et al., 2010a, 2010b). Atmospheric aerosols produced by both natural and anthropogenic processes are major players within Earth's climate system [Intergovernmental Panel on Climate Change (IPCC), 2001]. The impact of atmospheric aerosols on the earth's climate system is poorly understood, and is a subject of considerable interest for the scientific community as well as policy makers (Kaufman et al., 2002). Aerosol physical properties at a given location are largely governed by the local processes that lead to aerosol formation, which are modified by the prevailing meteorology, besides transport of aerosols from sources of nonlocal origin. Marine aerosols produced in the surf zone at high concentrations are immediately available for heterogeneous chemical reactions and influence the composition of aerosols at coastal locations [Vignati et al., 2001].

Satellite derived aerosol parameters are a cost-effective way to monitor and study aerosols distribution and effects over a long time period. Satellite data is a best source of global information about the aerosol optical depth (AOD) (Chu et al., 2003; King et al., 2003). Operational remote sensing of aerosols from long term satellites provides a means to achieve a global and seasonal characterization of aerosol. Satellite sensors view the entire earth and produce global images, thus resolving the spatial patterns resulting from the spatial in homogeneities of aerosol sources. Recently, several studies based on long-term records from the well-calibrated space instruments 
(e.g. Sea-viewingWide Field-of-view Sensor - SeaWiFS, Multi-angle Imaging SpectroRadiometer - MISR, and Moderate Resolution Imaging Spectroradiometer - MODIS, and Along Track Scanning Radiometer - ATSR) have contributed significantly to the understanding of global aerosol trends (Yoon et al., 2011; Zhang and Reid, 2010; Yu et al., 2009; Karnieli et al., 2009; Thomas et al., 2010). The current study focuses on the long-term temporal variation of Aerosol Optical Depth (AOD) over a tropical coastal location Machilipatnam (MPTM) of Andhra Pradesh state, (India) derived from OMI sensor.

\section{METHODOLGY AND DATA DESCRIPTION}

The Ozone Monitoring Instrument (OMI) is a nadir-viewing, wide-field-imaging UV and visible spectrometer designed to monitor ozone and other atmospheric species including aerosols. It is the key instrument on EOS AURA for monitoring the recovery of the ozone layer in response to the phase out of chemicals, such as CFCs. Global daily aerosol retrievals of Aerosol Optical Depth (AOD), produced from near UV observations by the Aura-OMI sensor. OMI aerosol retrievals at $388 \mathrm{~nm}$ are carried out over both land and ocean surfaces. OMI's near UV unique strength for aerosol detection is the large sensitivity to particle absorption as demonstrated by its predecessor the TOMS instrument. The results presented in this study used available Aerosol Optical Depth (AOD), retrieved from Level $30.25^{\circ} \times 0.25^{\circ}$ daily gridded OMI at $388 \mathrm{~nm}$ for a period of nine years from 2005 to 2013. The data for this study has been down loaded from the web portal http://disc.sci.gsfc.nasa.gov/giovanni. The daily time series of the OMI aerosol optical parameters were obtained by spatially averaging the OMAEROe retrievals (Torres et al., 2007) over the study locations. It was observed that stations selected for climatology studies were urban locations and hence $0.25 \times 0.25$ gridded data was found suitable and selected for this study. As selected sites for this study were costal urban locations, portion of ocean also become part of $0.25 \times 0.25$ satellite pixel along with urban land portion. The grid covers area of $25 \mathrm{~km}$ radius area around the domain so data presented here was accountable for surface reflectivities of both land and ocean features. Sub pixel contamination caused by ocean water bodies modifies reflectance reaching the sensor thereby perturb the aerosol retrievals and hence this study selected UV channel at $388 \mathrm{~nm}$ for aerosol climatology. Data is independent of surface characteristics at $388 \mathrm{~nm}$. In the present study statistical analysis carried for the study period 2005 -2013 to derive AOD trend over study location. 


\section{SITE PREVAILING SYNOPTIC METEOROLOGY}

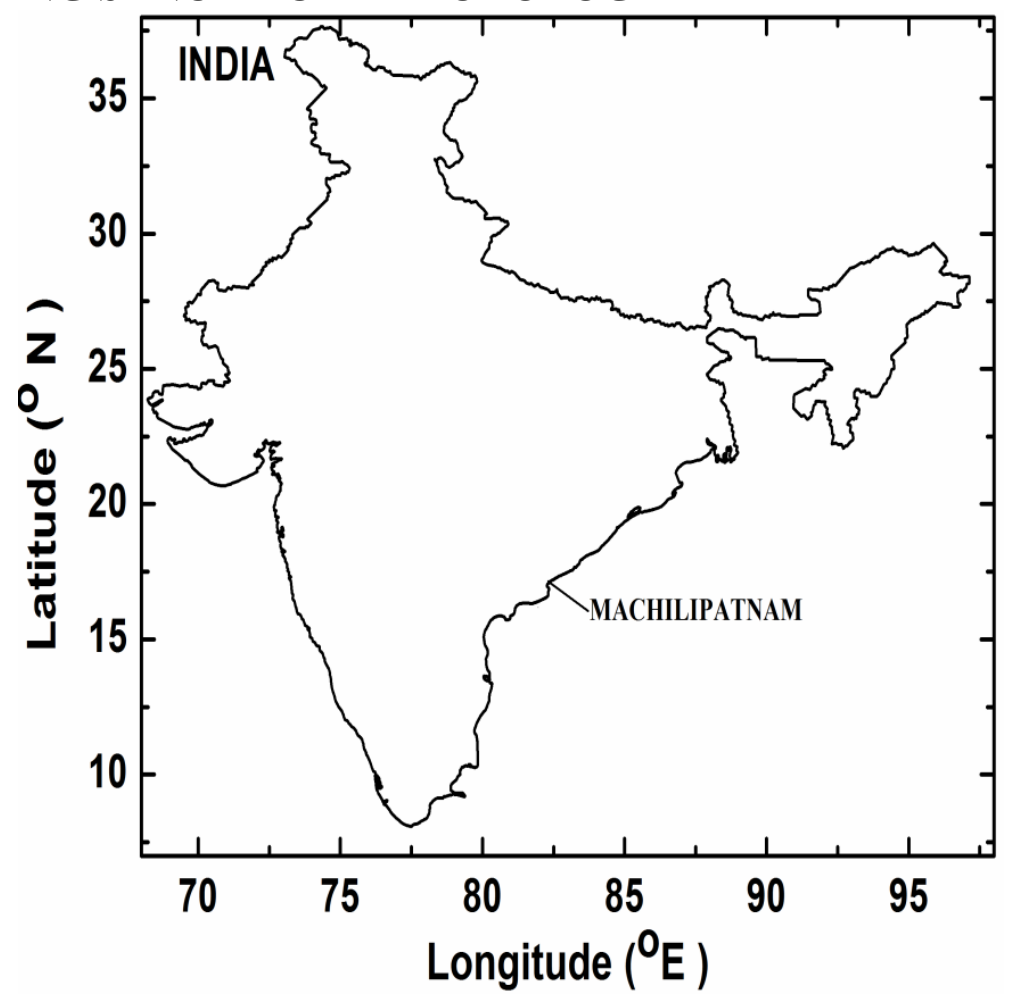

Fig.1 Geographical location of the site chosen for the study

Machilipatnam (MPTM) is an urban coastal location on the east coast of India. This urban location has population $\sim 1,70,008$ distributed over $\sim 26.67$ sq.km area. Machilipatnam $\left(16.7^{\circ} \mathrm{N}\right.$, $81.13^{\circ} \mathrm{E} ; 14 \mathrm{~m}$ asl) which close to the Bay of Bengal sea coast ( $\sim 1500 \mathrm{~m}$ away) and is subjected to the sea breeze activity on all days. The mixing region aerosols dispersed by the convection motion during the daytime remain there even after the sunset for about 4-6 h (Delage, 1974). Machilipatnam has big and small scale industries. Bharat Electronics Limited (BEL), a unit of the Union Defence Ministry, of the Government of India, operates a manufacturing unit in Machilipatnam. Factors such as Bay of Bengal (marine originated), local small industries, agriculture activities, domestic fossil fuel burning, anthropogenic activities, like fuel combustion, smoke, traffic emissions, and open burning sources etc., contribute to the aerosol concentration at this site.

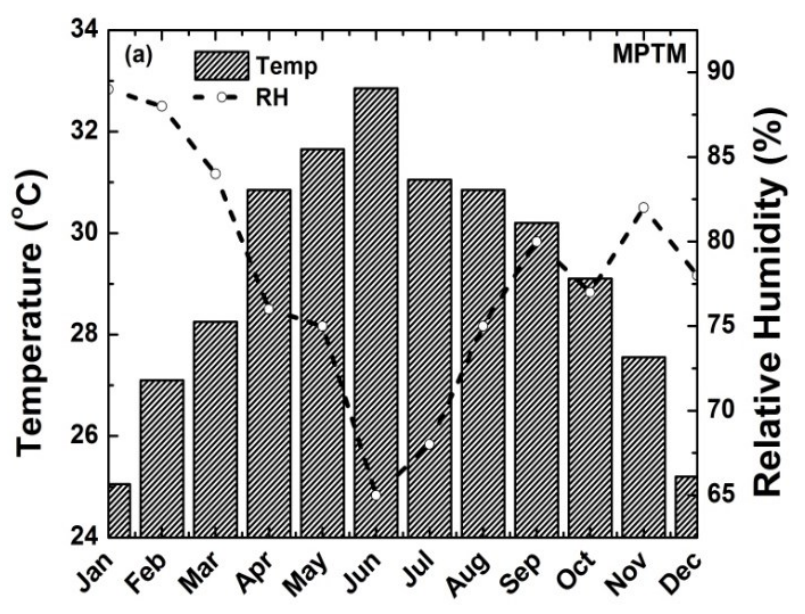




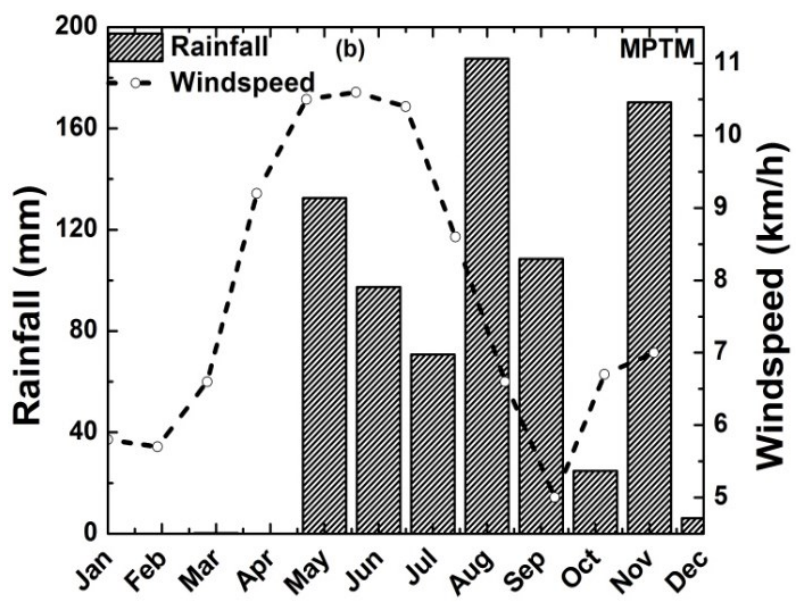

Fig.2 (a) monthly variations of surface temperature and relative humidity over MPTM (Top panel) and (b) monthly variation of total rain fall and wind speed over MPTM (bottom panel)

As MPTM is costal location, the prevailing synoptic meteorology is important in understanding the aerosol characteristics, transport mechanism and source apportionment. It has a tropical savannah climate with hot summers and moderate winters. The hottest months are between April and June. This study location is frequently hit by cyclones originating in the Bay of Bengal. The climatological monthly mean temperature, relative humidity $(\mathrm{RH}$ in \%), monthly accumulated rainfall (in $\mathrm{mm}$ ) and wind speed $(\mathrm{km} / \mathrm{h})$ is shown in the left and right panels of Fig. 2 respectively. This city gets most of its annual rainfall due to the southwest monsoon and winter monsoon which is active during October-December. June, with a monthly mean temperature $\sim 32.85^{\circ} \mathrm{C}$ is the warmest month; December is the coldest with mean temperature $\sim 25.2{ }^{\circ} \mathrm{C}$. RH varied almost inversely with temperature, June being the driest month with a value of $\sim 65 \%$. The average annual temperature is $\sim 27.05^{\circ} \mathrm{C}, \mathrm{RH} \sim 78.08 \%$, and total annual rainfall of $\sim 797.8 \mathrm{~mm}$ with a total number of 64 rainy days per year. The climatological mean rainfall pattern shows that considerable rain starts in May and peaks in August $(\sim 187.5 \mathrm{~mm})$. Based on the above factors, the calendar months are grouped into four distinct seasons according IMD (Indian meteorological department) viz. winter (December-February), summer (March-June), monsoon (July-September) and postmonsoon (October - November). Maximum wind speed found during June month with the mean $(\sim 10.6 \mathrm{~km} / \mathrm{h})$. Monsoon and post-monsoon months are characterized by moderate temperature (monthly mean temperature $\sim 30{ }^{\circ} \mathrm{C}$ ), maximum $\mathrm{RH}$ values $(\sim 75 \%$ ) and with total rainfall $\sim 700$ $\mathrm{mm}$. Winds are mostly westerly, easterly, North easterly depending on season (see Fig. 3). MPTM gets most of its annual rainfall due to the southwest monsoon.
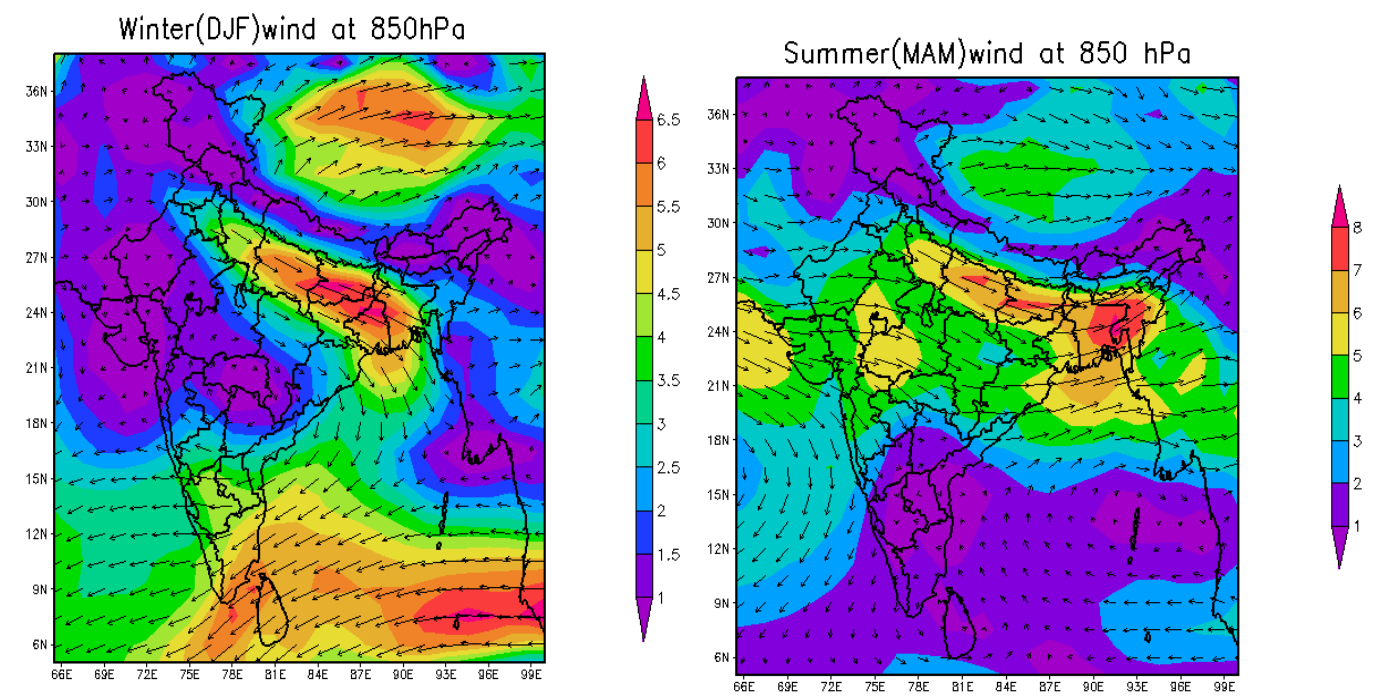

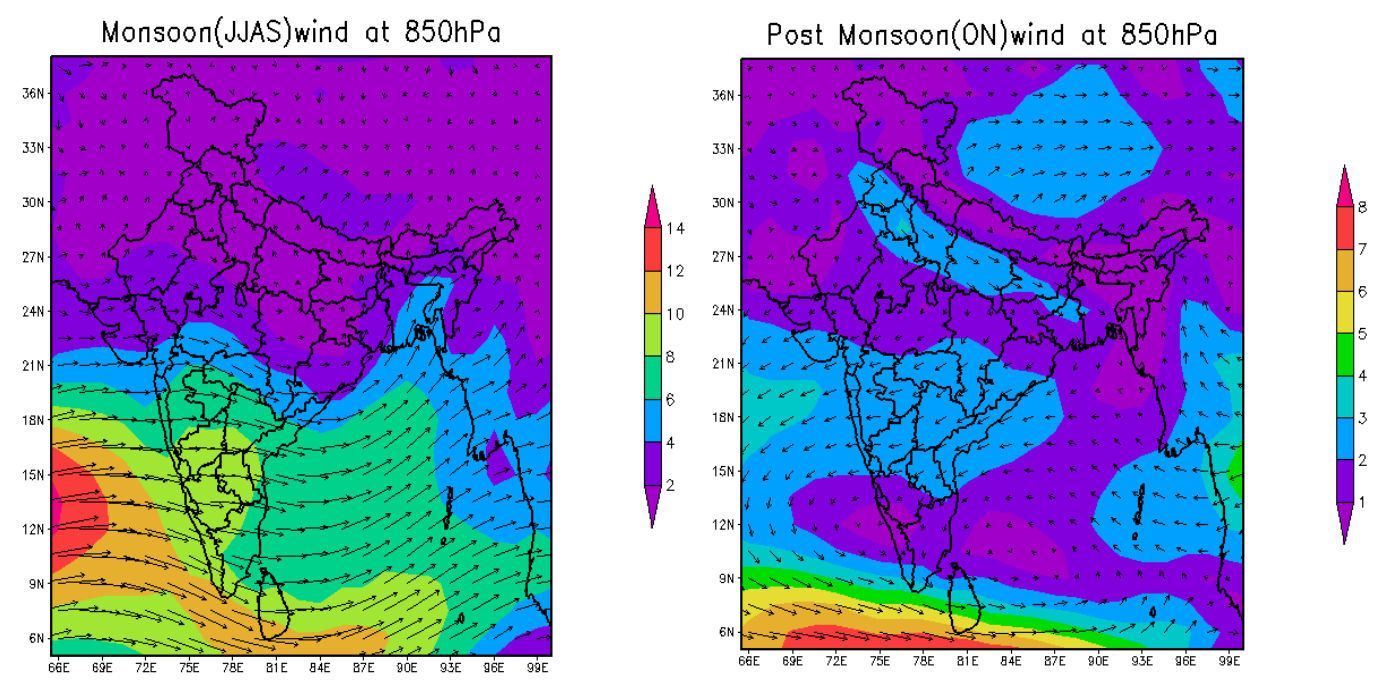

Fig. 3 Mean synoptic wind pattern at $850 \mathrm{hPa}$ for various seasons for the study period 2005-2013. Background colour indicates the magnitude of the wind speed.

\section{RESULTS AND DISCUSSION \\ 4.1 FREQUENCY DISTRIBUTION OF AODS}
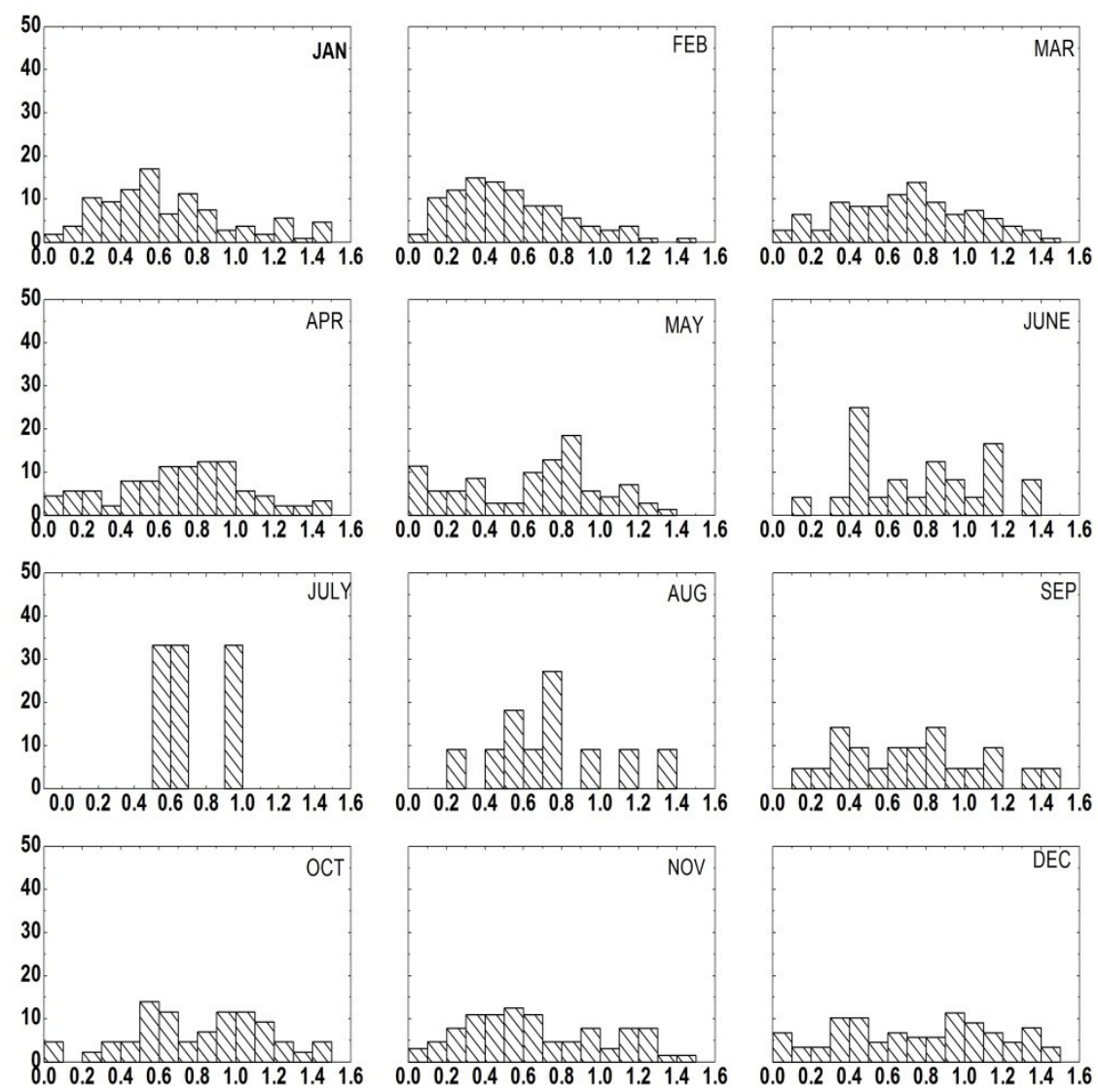

Fig. 4. Month-wise occurrence frequency distribution of the AODs for the study period.

Nine years (2005-2013) OMI AOD values are grouped into calendar months and their frequency distributions (in terms of percentage occurrence) are shown in Fig. 4. Size of the each bin is taken as 0.1. During January month, the occurrence of lower values $(<0.1$, first bin) of AOD is almost $\sim 5 \%$ and the percentage occurrence increased towards the higher AOD values. The occurrence of AOD values above 0.6 is almost $\sim 15 \%$. During February also, the pattern remained same for Higher AOD values, but the occurrence of lower values of AOD more compared to that of 
January. Towards summer months (March-June), the distribution is wider and a mode built up is clear with the maximum occurrence of AOD values shift toward relatively higher values around 0.2-0.6 ( $(30-40 \%)$. Distribution skewed towards higher AOD side. During the monsoon months (July-September), Occurrence of AOD values $(>0.6)$ were noticed and lowest values of AOD (first bin) diminished. During post-monsoon months (October and November), wider distribution was observed.

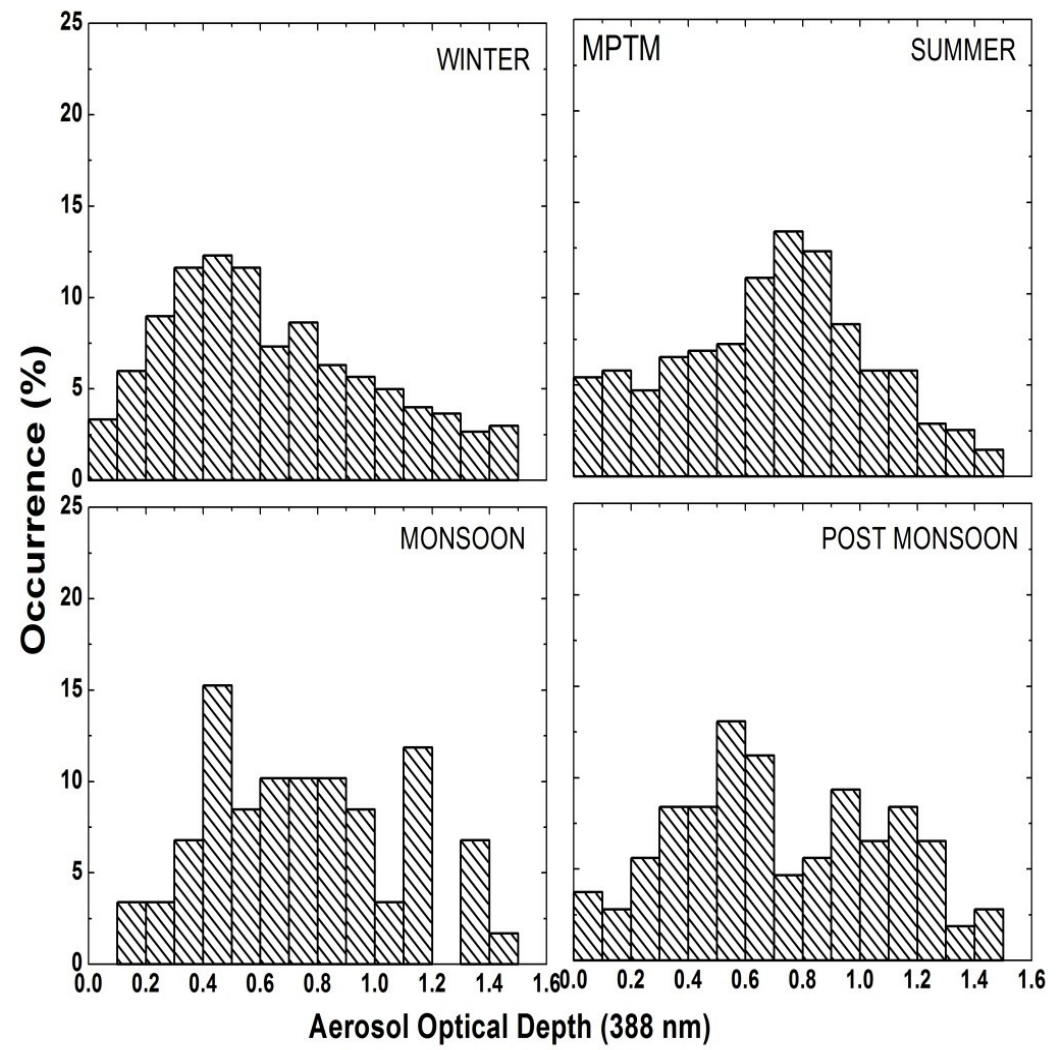

Fig. 5. Season-wise occurrence frequency distribution of the AODs for the study period.

Nine years (2005-2013) OMI AOD values are grouped into seasons and their frequency distributions (in terms of percentage occurrence) are shown in Fig. 5. The occurrence of AOD values between 0.1-0.6 found maximum during winter season thereafter percentage of occurrence decreased towards higher AOD values. During summer the percentage of occurrence found to be maximum for AODs with values greater than 0.7. The AOD values with values equal to 0.4 found to be occurred maximum during monsoon season. Similar pattern for AOD values with 0.3-0.5 $(\sim 15 \%$ occurrence) observed in post monsoon season over study location during study period.

\subsection{Seasonal variations}

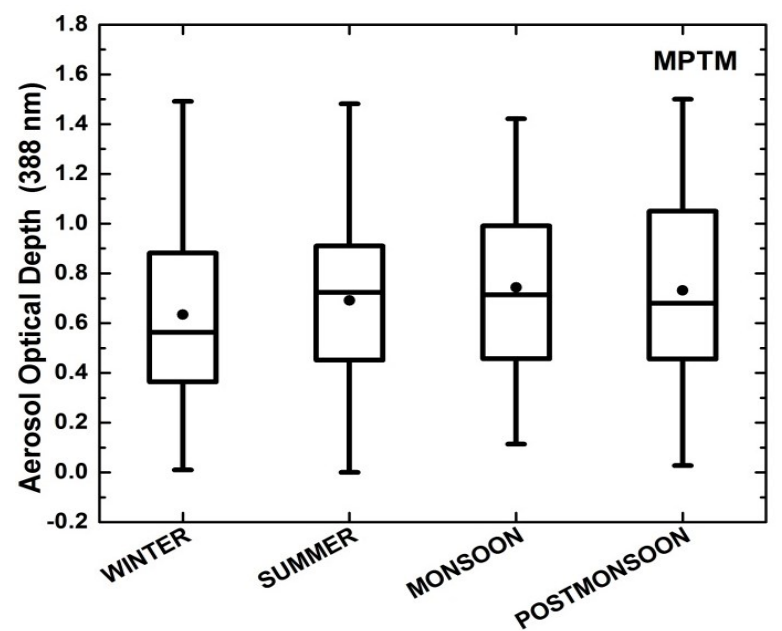

Fig. 6. Box and whisker plot for the seasonal mean variation for a period of 2005-2013 over MPTM. 
Seasonal mean variation of the AOD (OMI) values for the study period is shown as a box and whisker plot in Fig. 6. In Fig. 6, solid dots indicate the mean values; the range of the box indicates the 25 and 75 percentile values; centre line indicates the 50 percentile value (median); the range of the whiskers indicates the standard deviation of the mean value; dashes and crosses indicate the minimum, maximum values and the 1,99 percentile value of the dataset for the particular season. The seasonal mean AOD values along with other statistically meaningful parameters are given in Table 1. Each of the season mean value has been deduced from statistically significant number of daily AOD values. Only during July and August the dataset has fewer points (less than 100) due to the frequent spells of rainfall and cloudy skies.

Table. 1. Season wise OMI AOD statistics.

\begin{tabular}{|c|c|c|c|c|c|}
\hline \multirow{3}{*}{ Station } & Season & Mean AOD & $\boldsymbol{\sigma}$ & Median & $\begin{array}{c}\text { Number of } \\
\text { data } \\
\text { points }\end{array}$ \\
\hline \multirow{3}{*}{ MPTM } & Winter & 0.63414 & 0.35981 & 0.563 & 301 \\
\cline { 2 - 6 } & Summer & 0.69082 & 0.34605 & 0.723 & 276 \\
\cline { 2 - 6 } & Monsoon & 0.7432 & 0.33754 & 0.714 & 59 \\
\cline { 2 - 6 } & Post monsoon & 0.73136 & 0.3663 & 0.68 & 107 \\
\hline
\end{tabular}

From Fig. 6 the following gross features are evident (1) the mean AOD value is always higher than that of median except in summer season throughout the study period; (2) mean AOD value increased up monsoon thereafter decreased towards post monsoon; (3) the spread in values (in terms of the standard deviation) is highest in winter and least during monsoon; (4) highest seasonal mean AOD values are recorded during monsoon and the least seasonal mean value is in winter. The lowest seasonal mean OMI AOD value is recorded during winter with a value of $\sim 0.63 \pm 0.35$. The mean value increased towards summer reaching $\sim 0.69 \pm 0.34$ and attained peak in monsoon season with a value of $\sim 0.74 \pm 0.33$ and decreased during post-monsoon reaching as low as $\sim 0.73 \pm 0.3$.

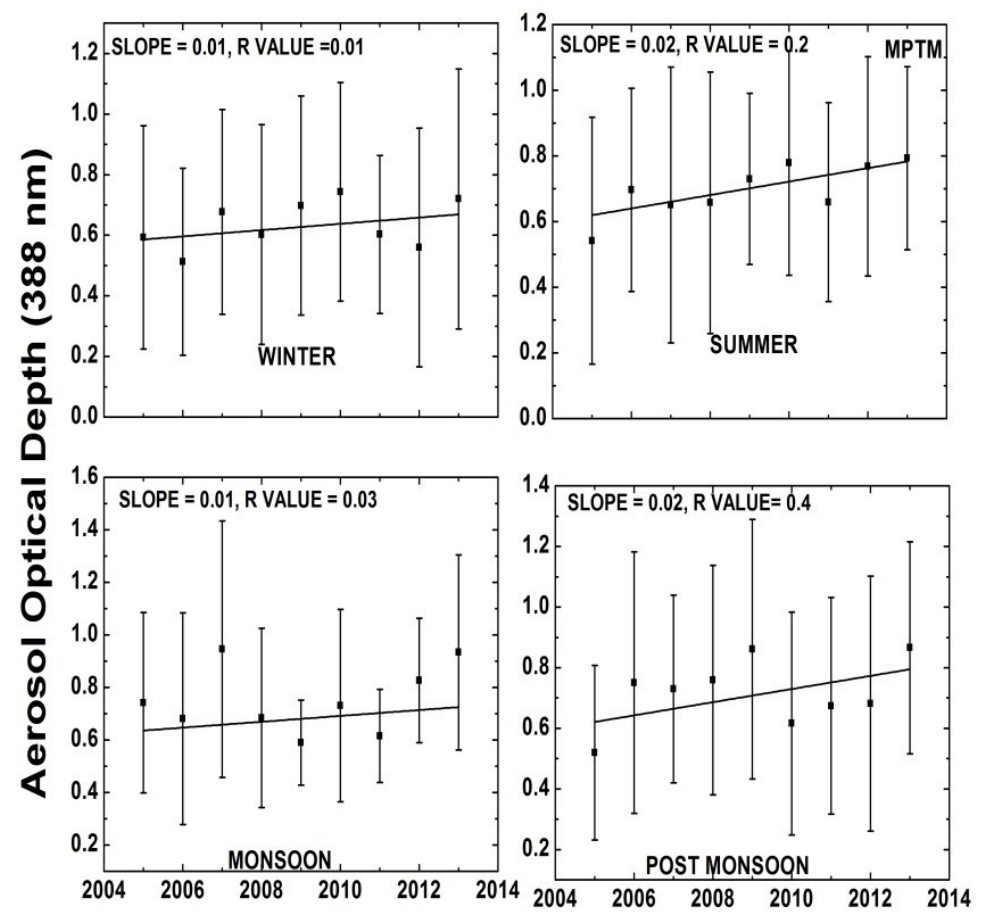

Fig. 7. Seasonal mean trend of AOD for a period of 2005-2013 over MPTM. 
Seasonal mean trend of OMI AOD for a period of 2005-2013 over study location observed from Fig. 7. It was noticed that during study period in all seasons AOD found to be increased. Positive slope of trend line found to be same in winter and monsoon but correlation coefficient found to be more in monsoon distribution. AOD showed increase during post monsoon for whole study period with slope value of trend line 0.02 and correlation coefficient 0.4 . From trend lines it was noticed that increase in mean AOD is not confined to a particular season during study period.

Apart from the local emissions and modulations of the aerosol concentrations with respect to the synoptic meteorological conditions, long-range transport also contributes to the columnar aerosol load. The transport of natural and anthropogenic aerosols critically depends upon the synoptic scale circulation pattern. The seasonally changing synoptic-scale meteorology is known to modulate the AOD periodically (intraseasonal/seasonal/annual and interannual time scales) through advection and precipitation (Moorthy et al., 2007a; Gogoi et al., 2009). Wind vector plots and back trajectory analysis provide the information about the synoptic circulation pattern and potential pathways of transport. The season-wise mean synoptic wind pattern (at $850 \mathrm{~h} \mathrm{~Pa}$ ) for the study period over the Indian subcontinent and surrounding regions is shown in Fig. 3. Over Indian region, the most important characteristic feature of synoptic meteorology comprises of seasonally changing air mass type and precipitation associated with the Asian summer monsoon from June to September. During the period from December to March, the prevailing winds are generally northeasterlies, from the inland continental regions toward the Indian Ocean, constituting a continental, dry air mass. The precipitation is rather insignificant, $\mathrm{RH}$ is low, and temperatures are in general low to moderate, except over the southern peninsula. During June to September, the steady onshore wind brings in moist marine air from the Indian Ocean over the continent through the Arabian Sea and Bay of Bengal, constituting the marine air mass. October-November and April-May months mark the transition from the moist marine air mass to dry continental air mass and vice versa ( Babu et al., 2013). Aerosol loading modulated by the mesoscale land/sea breezes arising out of the coastal proximity (Narayanan, 1967), which is perceptible during November to March. While the general circulation is a synoptic scale activity extending from June to October, the land/sea breeze is a mesoscale process occurring almost daily but confined within the boundary layer (Moorthy et al., 1993). Compared to these mesoscale land/sea breezes, the synoptic changes associated with the monsoon activity would produce more significant changes in the aerosol characteristics that would prevail for longer duration.

(Niranjan et al. 2004) over Visakhaptnam, a tropical coastal location of India reported the formation of new types of aerosols with completely different physical properties owing to mixing of the two different air masses, namely, continental and maritime indicating that the properties of aerosols are strongly dependent on the air mass history in a coastal environment and are a complicated mixture of marine, anthropogenic and rural aerosols (Moorthy et al., 1991, 1993; Vignati et al., 2001).

During winter, the winds reaching MPTM are mostly from northern India, Indo-Gangetic plains (IGP) via Bay of Bengal (BoB), often trajectories reaching East Asian countries. North Indian region including the IGP is believed to be highly aerosol laden owing to its dense industrial and urban areas. On the north of Indian sub-continent, the orography of the Himalayas act as a natural boundary to the dispersion of aerosols and low temperature conditions in winter leads to the confinement and build-up of aerosols. 


\subsection{INTER-ANNUAL VARIATIONS}

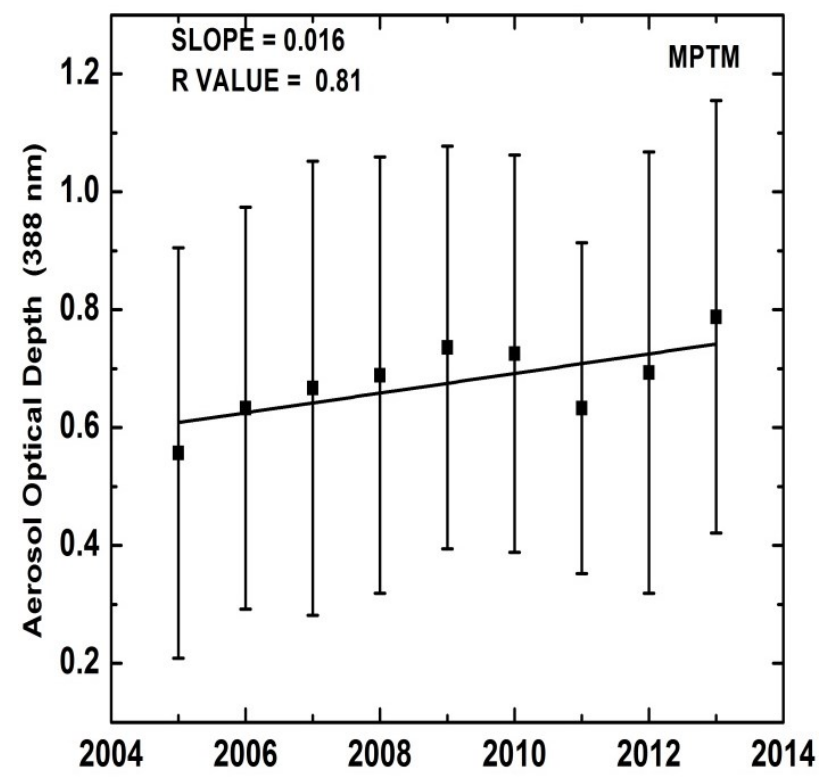

Fig. 8. Inter-annual variations of OMI mean AOD. Error bars indicate the standard deviation of the mean values. Solid line represents the linear least square fit.

The inter-annual variations in the mean AOD during the study period are shown in Fig. 8. The error bars in the figure represent the standard deviation from the mean value. The solid line represents the linear least square fit. The correlation coefficient was indicated on the respective plot. From the figure it is clear that annual mean AOD over MPTM is exhibiting an increasing trend. From the linear least square fit, the estimated increase in OMI AOD value per year is 0.016. However, the observed trend is highly dependent on the monthly and yearly data and averaging aerosol properties over distinct length datasets can introduce biases in the trends (Kaskaoutis et al., 2012). The discrepancy in the number of (satellite/ground) observations per temporal interval highly depends on the presence of cloud and its seasonal variation, which in turn can lead to serious uncertainties in the trend analysis leading to problems with the statistical representativeness (Yoon et al., 2011).

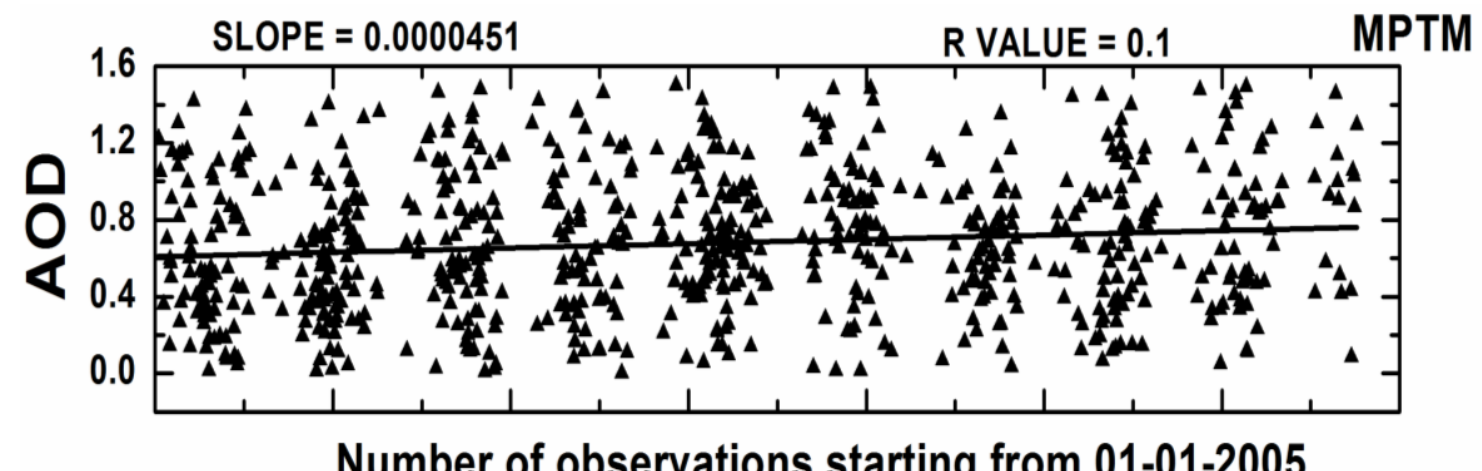

Fig.9. Long-term temporal variation of AOD at $388 \mathrm{~nm}$ over MPTM for the study period. Each symbol represents daily AOD at $388 \mathrm{~nm}$ and the solid line through the points represents the linear least squares fit indicating the long-term trend in AOD, its slope yielding the trend (year-1).

The positive slope of trend line observed from Fig. 9. The variation in AOD over all the study period found to be increased $\sim 0.0000451$. Urban expansion, population growth, increase in anthropogenic activities could be reasons for increasing trend of aerosol loading. 


\section{CONCLUSIONS}

Nine years (2005-2013) OMI aerosol optical depths (AOD at $388 \mathrm{~nm}$ ) have been analyzed to delineate the temporal variations in the aerosol columnar optical properties over Machilipatnam, India. The major conclusions drawn out of the study are

1. Aerosol loading found to be high in summer and monsoon seasons. Percentage of occurrence of AOD values greater than 0.6 found to be good in summer and monsoon seasons.

2. The mean AOD values increased towards summer reaching $\sim 0.69 \pm 0.34$ and attained peak in monsoon season with a value of $\sim 0.74 \pm 0.33$ and decreased during post-monsoon reaching as low as $\sim 0.73 \pm 0.3$.

3. Mean AOD shoed inter annual variations. Positive slope $\sim 0.016$ observed for trend line.

4. Apart from local sea breeze/land breeze activities, synoptic scale circulation found to be altered aerosol loading over study location.

5. Urban expansion, population growth, anthropogenic activities could be reasons for increasing trend of aerosol loading.

\section{References}

[1] Albrecht BA. (1989). Aerosols, cloud microphysics, and fractional cloudiness. Science 245: 1227-1230.

[2] Badrinath KVS, Madhavi Latha K. (2006), Direct radiative forcing from black carbon aerosols over urban environment. Advances in Space Research 37: 2183-2188.

[3] Chu DA, Kaufman YJ, Zibordi G, Chern JD, Mao J, Li C, Holben BN. (2003). Global monitoring of air pollution over land from EOS-Terra MODIS. Journal of Geophysical Research 108: 4661, DOI: 10.1029/2002JD003179.

[4] Delage, Y. (1974), A numerical study of the nocturnal atmospheric boundary layer, Q. J. R. Meteorol. Soc., 100, 351-364, doi:10.1002/qj.49710042507.

[5] Gogoi, M. M., K. K. Moorthy, S. S. Babu, and P. K. Bhuyan (2009), Climatology of columnar aerosol properties and the influence of synoptic conditions: First-time results from the northeastern region of India,J. Geophys. Res., 114, D08202, doi:10.1029/2008JD010765.

[6] Intergovernmental Panel on Climate Change (IPCC) (2001), Climate Change 2001: The Scientific Basis, Contribution of Working Group I to the Third Assessment Report of the Intergovernmental Panel on Climate Change, edited by J. T. Houghton et al., Cambridge Univ. Press, New York.

[7] Karnieli, A., Derimian, Y., Indoitu, R., Panov, N., Levy, R. C., Remer, L. A., Maenhaut, W., and Holben, B. N.: (2009), Temporal trend in anthropogenic sulfur aerosol transport from central and eastern Europe to Israel, J. Geophys. Res., 114, D00D19, doi: 10.1029/2009JD011870,

[8] Kaskaoutis, D.G., Singh, R.P., Gautam, R., Sharma, M., Kosmopoulos, P.G., Tripathi, S.N. (2012). Variability and trends of aerosol properties over Kanpur, Northern India using AERONET data (2001-2010). Environ.Res. Lett. 7, 024003,

[9] Khatri P, Ishizaka Y, Takamura T. (2009), A Study on aerosol optical properties in an urban atmosphere of Nagoya, Japan. Journal of the Meteorological Society of Japan 87: 19-38.

[10]King MD, Menzel WP, Kaufman, YJ, Tanre D, Gao BC., Platnic S, Ackerman SA, Remer LA, Pincus R, Hubanks PA. (2003). Cloud and aerosol properties, precipitable water, and profiles of temperature and humidity from MODIS. IEEE Transactions on Geoscience and Remote Sensing 41: 442-458.

[11] Moorthy, K. K., P. R. Nair, and B. V. Krishna Murthy (1991), Size distribution of coastal aerosols: Effects of local sources and sinks, J. Appl. Meteorol., 30, 844 - 852, doi:10.1175/1520-0450(1991)030<0844:SDOCAE $>2.0 . C O ; 2$. 
[12]Moorthy, K. K., B. V. K. Murthy, and P. R. Nair (1993), Sea breeze front effects on boundary layer aerosols at a tropical coastal station, J. Appl. Meteorol., 32, 1196 - 1205, doi:10.1175/1520-0450(1993)032<1196: $\mathrm{SBFEOB>2.0.CO;2.}$

[13] Moorthy, K. K., S. S. Babu, and S. K. Satheesh (2007a), Temporal heterogeneity in aerosol characteristics and the resulting radiative impact at a tropical coastal station - Part 1: Microphysical and optical properties, Ann. Geophys., 25, 2293-2308.

[14] Narayanan, V.: An observational study of the sea breeze at an equatorial coastal station, J. Appl. Meteorol., 18, 497-504, 1967.

[15] Panicker AS, Pandithurai G, Safai PD, Kewat S. (2008), Observations of enhanced aerosol longwave radiative forcing over an urban environment, Geophysical Research Letters 35: L04817, OI:10.1029/2007GL032879.

[16]Panicker AS, Pandithurai G, Safai PD, Dipu S, Lee DI. (2010a), on the contribution of black carbon to the composite aerosol radiative forcing over an urban environment. Atmospheric Environment 44: 3066-3070.

[17] Panicker AS, Pandithurai G, Dipu S. (2010b). Aerosol indirect effect during successive contrasting monsoon years over Indian sub-continent: using MODIS data. Atmospheric Environment 44: 1937-1943, DOI: 10.1016/j.atmosenv.2010.02.015.

[18] Ramanathan V, Crutzen PJ. (2003), New directions; atmospheric brown clouds. Atmospheric Environment 37: 4033-4035.

[19] Takamura T, Sugimoto N, Shimizu A, Uchiyama A, Yamazaki A, Aoki K, Nakajima T, Sohn BJ, Takenaka H. (2007). Aerosol radiative characteristics at Gosan, Korea, during the Atmospheric Brown Cloud East Asian Regional Experiment 2005. Journal of Geophysical Research 112: D22S36, DOI: 10.1029/2007JD008506.

[20] Thomas, G. E., Poulsen, C. A., Siddans, R., Sayer, A. M., Carboni, E., Marsh, S. H., Dean, S. M., Grainger, R. G., and Lawrence, B. N.: (2010).Validation of the GRAPE single view aerosol retrieval for ATSR-2 and insights into the long term global AOD trend over the ocean, Atmos. Chem. Phys., 10, 4849-4866, doi:10.5194/acp-10-4849-2010,

[21] Twomey S. (1977). The influence of pollution on the shortwave albedo of clouds. Journal of Atmospheric Science 34: 1149-1152.

[22] Vignati, E., G. de Leeuw, and R. Berkowicz (2001), Modeling coastal aerosol transport and effects of surf produced aerosols on process in the marine boundary layer, J. Geophys. Res., 106, 20,225 - 20,238, doi:10.1029/2000JD000025.

[23] Yoon, J., von Hoyningen-Huene, W., Vountas, M., and Burrows, J. P. (2011). Analysis of linear long-term trend of aerosol optical thickness derived from SeaWiFS using BAER over Europe and South China, Atmos. Chem. Phys., 11, 12149-12167, doi:10.5194/acp- 11-121492011,

[24] Yu, H., Chin, M., Remer, L. A., Kleidman, R. G., Bellouin, N., Bian, H., and Diehl, T. (2009), Variability of marine aerosol finemode fraction and estimates of anthropogenic aerosol component over cloud-free oceans from the Moderate Resolution Imaging Spectroradiometer (MODIS), J. Geophys. Res., 114, D10206, doi: 10.1029/2008JD010648,.

[25]Zhang, J. and Reid, J. S. (2010) A decadal regional and global trend analysis of the aerosol optical depth using a data-assimilation grade over-water MODIS and Level 2 MISR aerosol products, Atmos. Chem. Phys., 10, 10949-10963, doi:10.5194/acp-10- 10949-2010, 